\title{
As (re)configurações das demandas ao serviço social no âmbito dos serviços públicos de saúde*
}

\author{
Suely de Oliveira Bezerra** \\ Maria Arlete Duarte Araújo***
}

SUMÁRIO: 1. Introdução; 2. A redução do papel do Estado nos anos 1990 e as repercussões nas políticas sociais; 3. Um olhar sobre os anos 1980 para desvendar as políticas de saúde nos anos 1990; 4. Política de saúde nos anos 1990; 5. As (re)configurações das demandas postas ao serviço social no âmbito dos serviços públicos de saúde; 6 . Conclusões.

SUMMARY: 1. Introduction; 2 . The shrinking of the state's role in the nineties and the repercussions for social policies; 3 . A look on the eighties to reveal the health policies in the nineties; 4 . Health policy in the nineties; 5. The (re)configuration of the demands on social services within the public health services; 6 . Conclusions.

Palavras-chave: demandas profissionais; políticas de saúde; intervenção profissional.

KEY WORDS: professional demands; health policies; professional intervention.

Este artigo estuda as demandas impostas ao fazer profissional dos assistentes sociais na esfera pública dos serviços de saúde, a partir da redefinição do papel do Estado nos anos 1990. Inicialmente, discorre sobre o caráter reducionista do Estado à luz da política neoliberal implementada pelo go-

\footnotetext{
* Artigo recebido em out. 2005 e aceito em jul. 2006.

** Mestre em serviço social, professora do Departamento de Serviço Social da Universidade Federal do Rio Grande do Norte, UFRN. Endereço: Av. Praia de Genipabu, 2100 — Condomínio Corais do Atlântico Bloco Noronha, ap.1301— Ponta Negra — CEP 59094-010, Natal, RN, Brasil. E-mail: susubezerra@ig.com.br.

*** Doutora em administração de empresas pela FGV-SP, diretora do Centro de Ciências Sociais Aplicadas da UFRN e professora do Programa de Pós-Graduação em Administração da UFRN. Endereço: Av. Rodrigues Alves, 410/1100 — Residencial Maria José Gurgel — Petrópolis CEP 59020-200, Natal, RN, Brasil. E-mail: dfb@digi.com.br.
} 
verno brasileiro. Depois, lança um olhar sobre as políticas de saúde nos anos 1980 para explicitar as repercussões nos serviços públicos de saúde nos anos 1990. Por último, delineia as configurações e reconfigurações das demandas dirigidas ao serviço social no âmbito dos serviços públicos de saúde e aponta para a necessidade de uma leitura atenta das determinações sociais, históricas, econômicas, políticas e culturais nas expressões da questão social na saúde e, especialmente, das limitações da intervenção profissional nos processos relacionados ao binômio saúde-doença, uma vez que estão atrelados aos processos societários em nível macro.

\section{The (re)configuration of demands on social services within the} public health services

This article studies the demands on the professional activities of social workers in public health services when the state's role was redefined in the nineties. It first discusses the reductionist character of the state in light of the neo-liberal policies implemented by the Brazilian government. It then examines health policies in the eighties in order to identify the repercussions for public health services in the nineties. Finally, it establishes the configurations and reconfigurations of the demands on social services within the public health services. The article points out that one has to take a closer look on the social, historical, economic, political, and cultural determinants of social and health issues, especially in the limitations of professional intervention in the processes related to the health-illness binomial, since they are tied to macro-level societary processes.

\section{Introdução}

As mudanças no mundo do trabalho interferem muito nas condições de vida dos trabalhadores, determinando a forma como vivem, adoecem e morrem. Profissão inserida na divisão social e técnica do trabalho, o serviço social também se depara com as exigências postas pelo processo de reestruturação do mundo do trabalho, particularmente nos serviços públicos, onde está a maioria dos assistentes sociais em um contexto de precarização do trabalho e de Estado mínimo para a implementação das políticas sociais públicas.

Assim, o estudo das demandas postas para o fazer profissional dos assistentes sociais, no âmbito da esfera pública dos serviços de saúde, pressupõe entender o contexto em que elas se inserem, a partir das determinações que se colocam como definidoras de suas configurações e reconfigurações. 
Para apreender as demandas, este artigo fala, inicialmente, sobre o caráter reducionista do Estado à luz da política neoliberal implementada a partir dos anos 1990 pelo governo brasileiro e suas implicações nas políticas sociais públicas. Em seguida, lança um rápido olhar sobre as políticas de saúde nos anos 1980, para explicitar as repercussões da reestruturação nos serviços públicos de saúde nos anos 1990. Por último, delineia as configurações e reconfigurações das demandas dirigidas ao serviço social no âmbito dos serviços públicos de saúde e tece algumas considerações finais.

\title{
2. A redução do papel do Estado nos anos 1990 e as repercussões nas políticas sociais
}

A política de cunho neoliberal implementada no governo Collor e intensificada na gestão de Fernando Henrique Cardoso teve como proposta a defesa do mercado como espaço privilegiado das relações sociais e a redução do papel do Estado no que se refere à esfera da regulação do trabalho e prestação de serviços públicos.

Embora o ajuste fiscal, a desregulamentação trabalhista e as privatizações tivessem como argumento a necessidade do Estado atuar de forma eficiente e eficaz em outras áreas, o que se viu, principalmente nos anos 1990, foi a utilização do receituário neoliberal, traduzido na visão de Netto (2000:79-81) na

\begin{abstract}
inviabilização da alternativa constitucional da construção de um Estado com amplas responsabilidades sociais, garantidor de direitos sociais universalizados (através do) (...)tratamento negativo das políticas sociais, tal como se compreendiam no arcabouço constitucional de 1988, (que) funcionou duplamente: de um lado, forneceu elementos para justificar a impossibilidade de assegurar aqueles direitos; de outro, instaurou condições para institucionalizar políticas sociais convenientes e adequadas ao projeto político de que FHC se fez condutor.
\end{abstract}

Em decorrência, verificou-se o enxugamento da máquina pública por meio da privatização de seus órgãos e a desorganização e sucateamento dos serviços sociais públicos. Tal política resultou na desresponsabilização do Estado de suas obrigações sociais, que segundo Iamamoto (1998:43) leva a

uma transferência, para a sociedade civil, de parcela das iniciativas para o atendimento das seqüelas da questão social. (...) Por outro lado, constata-se 
uma tendência à refilantropização social, em que grandes corporações econômicas passam a se preocupar e a intervir na questão social dentro de uma perspectiva de filantropia empresarial.

Significa dizer que, por um lado, a sociedade civil, por meio de entidades não-governamentais e de programas de voluntariado, toma para si a tarefa de prestar serviços que constitucionalmente são deveres do Estado e, por outro, o empresariado, com iniciativas na área da educação, saúde, esporte, lazer, meio ambiente etc., assume o papel de benemérito das causas sociais.

Esse processo de tirar a responsabilidade do Estado vai de encontro aos preceitos contidos na Constituição de 1988 que reiterava e efetivava direitos. Na verdade, há um desmantelamento dessa lógica e a sua substituição por outra, que desloca os direitos sociais garantidos do ponto de vista formal, e põe em seu lugar a bandeira da solidariedade, despolitizando o atendimento das necessidades humanas básicas dos indivíduos.

De acordo com Netto (2000:81-88), o governo dos anos 1990 caracterizou-se pela sabotagem das políticas sociais em três vertentes: no estrangulamento na alocação de recursos, na manipulação das receitas e no desvio dos recursos destinados às políticas sociais públicas.

O estrangulamento na alocação de recursos diz respeito à contenção ou à redução dos recursos destinados à implementação das políticas sociais, resultando no sucateamento dos serviços públicos responsáveis pela execução das referidas políticas.

Essa realidade se torna concreta no cotidiano de quem busca os serviços públicos, particularmente a saúde, onde o quadro de precariedade se faz sentir pela ausência de produtos elementares para os procedimentos mais simples; de profissionais de diversas áreas; de equipamentos, seja pela falta de manutenção, seja pela inexistência ou pelo número inferior à demanda do setor.

No tocante à saúde, a única alteração positiva deveu-se à implementação da contribuição provisória sobre movimentação financeira (CPMF) para financiar os gastos nessa área. Os recursos destinados à saúde apresentaram nos anos 1990 os dados apresentados na tabela 1.

As informações constantes na tabela 1 demonstram que o aumento percentual de $15,6 \%$ destinado à saúde, em função da criação da CPMF, não durou muito e já no ano seguinte teve uma queda de quase quatro pontos percentuais. 


\begin{tabular}{|ccc|}
\hline \multicolumn{3}{c|}{$\begin{array}{c}\text { Tabela 1 } \\
\text { Destinação de recursos para o setor saúde }\end{array}$} \\
\hline \multirow{2}{*}{ Período } & $\begin{array}{c}\text { Recursos autorizados } \\
\text { (em bilhões de reais) }\end{array}$ & $\begin{array}{c}\text { Evolução percentual } \\
\text { dos recursos (\%) }\end{array}$ \\
\hline 1995 & 19.962 & - \\
1996 & 18.583 & 15,6 \\
1997 & 21.498 & 11 \\
1998 & 19.101 & \\
\hline Fonte: Netto, 2000. & & \\
\hline
\end{tabular}

Na assistência e previdência social os cortes orçamentários também se fizeram sentir, como podemos ver na tabela 2 .

\begin{tabular}{|cc|}
\hline \multicolumn{2}{c|}{$\begin{array}{c}\text { Tabela 2 } \\
\text { Percentual de gastos federais em relação aos totais } \\
\text { da receita tributária }\end{array}$} \\
\hline Período & $\%$ \\
\hline 1995 & 43,4 \\
1996 & 40,1 \\
1997 & 39,9 \\
1998 & 39,1 \\
\hline Fonte: Netto, 2000.
\end{tabular}

Os dados comprovam e reforçam o distanciamento do Estado brasileiro da resolução das questões sociais, pela redução do financiamento e, conseqüentemente, de investimentos em uma área que concentra um grande contingente de pessoas demandantes de políticas sociais públicas, em função da complexificação das seqüelas originadas pela política de exclusão implementada no país ao longo dos anos e intensificada nos anos 1990.

No que se refere à manipulação das receitas, Netto (2000:84) afirma que:

No sistemático processo de sabotagem das políticas sociais que tem a massa dos trabalhadores como usuários, o governo FHC não se limitou ao procedimento dos cortes - valeu-se amplamente da manipulação de receitas, desviadas de seus fins precípuos para outras finalidades (...) Esse "método" foi 
largamente empregado para inviabilizar talvez a mais significativa das conquistas democrático-sociais consagradas na Constituição de 1988 - aquela referente à seguridade social (que) projetava uma radical transformação nas práticas políticas sociais implementadas no país: rompia com o casuísmo, o emergencialismo e a dispersão das políticas setoriais.

Isso significa dizer que mesmo os recursos autorizados para as políticas sociais públicas, em particular as da seguridade social, foram desviados para fins diversos daqueles definidos pelo Orçamento Geral da União. De acordo com Luiz Alberto dos Santos, especialista em políticas públicas e gestão governamental, por meio de estudo da Assessoria de Orçamento e Fiscalização Financeira da Câmara dos Deputados, de fevereiro de 1999 (Netto, 2000:85),

apenas no ano de 1997, a utilização do Fundo de Estabilização Fiscal permitiu que cerca de $\mathrm{R} \$ 2,8$ bilhões fossem desviados da seguridade social para outras despesas; para 1988, a estimativa é que este desvio atinja pelo menos R \$ 3,3 bilhões. Ao mesmo tempo, o Tesouro repassa cada vez menos recursos para a seguridade (em 1997, as fontes fiscais no orçamento da seguridade corresponderam a apenas $1,5 \%$ de suas despesas, contra 10,5\% em 1995 e 16\% em 1996), enquanto as despesas com encargos previdenciários da União custeados com recursos da seguridade vêm crescendo ano a ano: em 1997, cerca de 14 bilhões de EPU foram financiados com estes recursos. Dados disponibilizados pela Anfip apontam na mesma direção: segundo a entidade, nada menos que R $\$ 26$ bilhões deixaram de ser transferidos ao INSS pelo Tesouro nos últimos três anos, em vista do pagamento de benefícios sem fonte de custeio própria e que deveriam ser bancados por recursos fiscais (e conclui afirmando que) não existe [...] déficit da seguridade social, mas, na verdade, uma apropriação do orçamento e das receitas da seguridade para financiar despesas que deveriam ser custeadas pelo Tesouro com fontes fiscais.

As informações evidenciadas dão conta das iniciativas para conter os avanços na área social, colocadas na Constituição de 1988, e possibilitar a veiculação de uma política de retração do Estado em relação às políticas sociais públicas.

No que diz respeito aos recursos desviados das políticas sociais públicas, eles tiveram como destino os setores de interesse do grande capital, quais sejam: o pagamento das dívidas interna e externa, cujos juros extorsivos levam a um aumento dos encargos dos valores das dívidas, obrigando o país a pagar inúmeras vezes o valor inicialmente emprestado. 
Paralelamente, as políticas sociais públicas vão sendo esvaziadas com coberturas deficitárias, do ponto de vista da oferta e da demanda e pela desqualificação dos serviços prestados, decorrente do sucateamento e precarização a que estes estão submetidos.

Em conseqüência, as políticas sociais estão postas no projeto político das elites brasileiras de forma subalternizada, impossibilitando, como diz Netto (2000:86),

uma articulação de política social, pública e imperativa, cujo formato tenha como suporte um Estado que ponha limites políticos democráticos à lógica do capital; o que o projeto político do grande capital exclui é um padrão de política social (...) que tenha por eixo uma função democrático-reguladora em face do mercado (...).

Ou seja, as políticas sociais estão inseridas no projeto do grande capital, mas submetidas aos parâmetros mercantis, uma vez que a base de acesso passa a ser contributiva. Essa lógica impede a universalização da cobertura e segmenta a população demandante, delimitando o nível de qualidade dos serviços prestados.

Consubstancia-se, dessa forma, não somente o descaso, mas a própria desresponsabilização do Estado e suas obrigações legais, como veremos na análise das políticas de saúde.

\section{Um olhar sobre os anos 1980 para desvendar as políticas de saúde nos anos 1990}

A política de saúde implementada no Brasil, nos anos 1980, situa-se em um contexto de ascensão dos movimentos sociais, no bojo do movimento de democratização do país, onde concepções e práticas são questionadas e novas formas de ver, pensar, sentir e agir ganham espaço, inclusive institucional, resultando em novas correlações de força entre as elites dominantes e os trabalhadores.

Vários foram os movimentos, em diversos setores da sociedade, que se fizeram presentes naquela década, sendo o mais emblemático de todos eles o movimento Diretas Já, que mobilizou todo o país a conclamar por eleição direta para o primeiro presidente da República pós-Golpe de 64 .

Em particular, no setor saúde, evidenciou-se o movimento da reforma sanitária, cujas discussões permearam, em maior ou menor grau, o país de norte a sul e tiveram como saldo o entendimento da saúde como direito, re- 
sultante das condições de vida de um povo no que tange ao trabalho e à renda, à moradia, à distribuição de terras, à educação, à alimentação, ao lazer, à participação política e social, com princípios de universalidade, integralidade e eqüidade sob a responsabilidade do Estado.

Assim, no início dos anos 1980, procurou-se consolidar o processo de expansão da cobertura assistencial, iniciado na segunda metade dos anos 1970, para atender às formulações estabelecidas na Organização Mundial de Saúde (OMS) na Conferência de Alma-Ata (1978), que tinha como meta "Saúde para todos no ano 2000", tendo como foco a atenção primária à saúde.

Várias foram as propostas de implantação de uma rede de serviços voltada para a atenção primária à saúde com princípios de universalização, hierarquização e descentralização. Nessa ótica, em 1976 é implementado o Programa de Interiorização das Ações de Saúde e Saneamento (Piass), que de acordo com Tanaka e colaboradores (1992:4) destinava-se a

\begin{abstract}
implantar e implementar uma estrutura de rede básica de serviços de assistência médico-sanitária em locais de baixa densidade demográfica, sobretudo na região nordeste do país. (...) O Piass tinha como diretrizes básicas a utilização ampla de pessoal de nível auxiliar, com ênfase nas atividades preventivas e previa a integração em nível local dos diferentes serviços de saúde sob a responsabilidade das secretarias estaduais de saúde.
\end{abstract}

Em agosto de 1980 é iniciada a elaboração do Programa Nacional de Serviços Básicos de Saúde (Previ-Saúde) que nunca saiu do papel.

De acordo com Tomazi (1986:73-75) o Previ-Saúde teria como objetivo:

\begin{abstract}
A extensão dos serviços de saúde a toda a população brasileira, o mais rapidamente possível, ampliando a implantação acelerada de uma rede básica de unidades de saúde de cobertura universal, com prioridades para as populações dos pequenos centros urbanos e da periferia das grandes cidades.
\end{abstract}

Na verdade, o Previ-Saúde não foi implementado sob o argumento definido pela Federação Brasileira de Hospitais e o próprio Inamps — de que era um plano estatizante, foi elaborado o Plano de Reorientação da Assistência à Saúde no âmbito da Previdência Social, em agosto de 1982, mais conhecido como Plano do Conasp, a partir do qual foi implementada a política de ações integradas de saúde (AIS), em 1983.

O Conasp tinha entre outros objetivos uma maior utilização da rede pública de serviços básicos de saúde. Para tal, implantou-se um convênio 
trilateral entre Ministério de Previdência e Assistência Social, Ministério da Saúde e secretarias estaduais de Saúde. As ações integradas de saúde (AIS) substituem esses convênios e têm como foco: a municipalização dos serviços de saúde como diretriz de trabalho, o fortalecimento das comissões interinstitucionais como mecanismo de gerência e a democratização efetiva dos serviços como instrumento de crescimento técnico-administrativo e operacional.

Isso significa dizer, por um lado, que a acessibilidade aos serviços de saúde ocorre sem o critério de vínculo empregatício da população demandante do serviço. Por outro lado, a descentralização possibilita que os recursos financeiros cheguem aos municípios oportunizando o desenvolvimento de ações em saúde mais próximas de suas necessidades específicas.

Nessa ótica, o Estado brasileiro passou gradativamente a reassumir a questão da saúde de uma forma mais efetiva do que nas duas décadas anteriores, uma vez que, a partir de 1964, houve uma redução drástica nos investimentos no setor saúde, ocasionando o fortalecimento da iniciativa privada no setor.

Simultaneamente, começa a tomar corpo o movimento da reforma sanitária brasileira, constituído inicialmente por uma parcela da intelectualidade universitária e por profissionais da área da saúde e, posteriormente, por outros segmentos da sociedade, como parlamentares progressistas, centrais sindicais e movimentos populares de saúde.

As propostas desse movimento, iniciado em pleno regime autoritário da ditadura militar, eram direcionadas fundamentalmente à construção de uma política de saúde efetivamente democrática, cujos elementos essenciais para a reforma do setor eram a descentralização, universalização e unificação das ações. O marco histórico do movimento foi a VIII Conferência Nacional de Saúde, em março de 1988, que consagra os princípios apregoados pelo movimento da reforma sanitária.

Em 1987 é implantado o Sistema Unificado e Descentralizado de Saúde (Suds) como uma consolidação das ações integradas de saúde, adotando como diretrizes a universalização e a eqüidade no acesso aos serviços; a integralidade dos cuidados; a regionalização dos serviços de saúde e a implementação de distritos sanitários; o desenvolvimento de instituições colegiadas gestoras e o desenvolvimento de política de recursos humanos.

Em outubro de 1988 é promulgada a nova Constituição Federal e o capítulo referente à saúde reflete todo o processo desenvolvido ao longo dos anos 1970 e 80, criando o Sistema Único de Saúde (SUS) e estabelecendo no art. 196, que "a saúde é direito de todos e dever do Estado" (Brasil, 1988:202).

A Constituição prevê, ainda, o acesso universal e igualitário às ações e serviços de saúde, com regionalização e hierarquização, descentralização com 
direção única em cada esfera de governo, participação e controle da população e atendimento integral, com prioridade para as atividades preventivas, sem prejuízo dos serviços assistenciais.

Entretanto, a mudança na conjuntura logo se faz sentir. Os setores contrários aos preceitos constitucionais na área da saúde articulam-se e viabilizam um desmonte no processo de implementação do SUS, que deveria ser efetuado a partir dos referenciais definidos pela Constituição Cidadã.

Esse desmonte vai ser implementado de forma incisiva nos anos 1990, atropelando os princípios do SUS, desencadeando, assim, uma série de distorções, de forma a impossibilitar a sua efetivação.

Nesse sentido, a universalidade e a integralidade se esvaziam não pela negação do acesso por não portar uma carteira de segurado e pela falta de definição dos níveis de atenção, mas pela falta de condições de atendimento dos serviços de saúde; a descentralização, em muitos casos, é sinônimo de prefeiturização e a eqüidade dá lugar ao tráfico de influências e aos jeitinhos para ter acesso ao sistema de saúde.

\section{Política de saúde nos anos 1990}

As mudanças trazem em seu lastro toda a contraditoriedade própria de uma esfera, cuja função na sociedade capitalista é mediar os conflitos de interesses entre capital e trabalho e que, embora esteja a serviço das elites dominantes, tem que incorporar também, em certa medida, as lutas e as conquistas dos trabalhadores, dependendo da correlação de forças estabelecidas na conjuntura.

Retomando o texto constitucional, evidencia-se que para instituir a saúde como direito e dever do Estado, constitui-se condição essencial implementar o Sistema Único de Saúde (SUS), que tem como princípios e diretrizes a universalidade, a eqüidade, a integralidade, a descentralização, a hierarquização e o controle popular.

O SUS foi regulamentado pela Lei Orgânica da Saúde no $n^{\circ} .080 / 90^{1}$ e é composto por centros e postos de saúde, hospitais — incluindo os universitári-

\footnotetext{
${ }^{1}$ Dispõe sobre as condições para a promoção, a proteção e a recuperação da saúde, a organização e o funcionamento dos serviços correspondentes, definindo os parâmetros para o modelo assistencial e estabelecendo os papéis das três esferas de governo (Ministério da Saúde, 1993). Institui ainda o Sistema Único de Saúde (Ministério da Saúde. Escola Nacional de Saúde Pública Sérgio Arouca). Disponível em: <www.ensp.fiocruz.br>. Acesso em: 20 out. 2004.
} 
os -, laboratórios, hemocentros (bancos de sangue), fundações e institutos de pesquisa, sendo o seu financiamento realizado por meio dos recursos arrecadados, via impostos e contribuições sociais pagos pela população, que compõem os fundos dos governos federal, estadual e municipal.

Por meio do SUS, todos os cidadãos deveriam ter direito às consultas, exames, internações e tratamentos nas unidades de saúde vinculadas ao sistema, sejam públicas ou privadas, sendo as últimas contratadas pelo gestor público de saúde. A vigilância epidemiológica também é de responsabilidade do SUS, assim como o controle da qualidade de remédios, de exames, de alimentos, higiene e adequação de instalações que atendem ao público.

O Sistema Único de Saúde deve promover a saúde através de ações preventivas e curativas, democratizando as informações relevantes para o conhecimento da população quanto aos seus direitos e os riscos à sua saúde.

O SUS é constituído pelos serviços públicos de saúde nas esferas federal, estadual e municipal e pelos serviços privados de saúde, sejam eles filantrópicos, lucrativos, beneficentes etc.

No que tange aos serviços públicos de saúde, estes são prestados pela esfera governamental ou pela terceirização do serviço. Atende os setores de média e baixa rendas e são financiados pelas contribuições compulsórias à Previdência Social.

A partir dos anos 1990, outras fontes de receita foram incorporadas a esse fundo administrado pelo Estado, tais como a contribuição provisória sobre movimentação financeira (CPMF), a contribuição para financiamento da seguridade social (Cofins) e a contribuição sobre o lucro líquido das empresas (CSLL).

No que se refere à prestação privada dos serviços e seguro privado, eles são destinados aos setores de renda mais elevada e parcelas de trabalhadores urbanos e de serviços.

Tais traços resultam em um sistema fragmentado e desarticulado no acesso e na prestação dos serviços de saúde, incapaz de dar respostas efetivas às necessidades da população que demanda esses serviços, impermeável a um controle público efetivo e causador da dicotomia entre as ações individuais e coletivas de saúde.

Ainda, conforme Elias (2001:70),

este "sistema" configurado socialmente, isto é reconhecido na prática da estruturação dos serviços, contraria em grande medida os preceitos constitucionais e legais, tradicionalmente geradores de direitos sociais nos países capitalistas centrais. Assim, as exigências para a adoção de critérios de universalização, da igualdade no tratamento assistencial, da eqüidade e da 
participação na implementação do Sistema de Saúde subsistem apenas no plano jurídico legal, e no caso brasileiro são concessões apenas retóricas, carecendo de efetividade, isto é, não são adotadas como direitos a nortearem o cotidiano das ações e da prestação de serviços na saúde.

Para atender o princípio do controle popular, a Lei Orgânica da Saúde (no 8.142/1990) ${ }^{2}$ estabelece duas formas de participação da população na gestão do SUS: as conferências e os conselhos de saúde.

As conferências - municipais, estaduais e nacional — devem acontecer de quatro em quatro anos e têm a finalidade de avaliar e propor diretrizes para as políticas públicas de saúde. Seus representantes são os usuários do SUS, do governo, dos profissionais de saúde, dos prestadores de serviços, parlamentares e outros.

Quanto aos conselhos de saúde - municipais, estaduais e federais eles são órgãos de controle social do SUS. Os conselhos de saúde funcionam como colegiados e têm caráter deliberativo. São componentes dos conselhos os representantes do governo, dos prestadores de serviços, dos profissionais de saúde e usuários.

De acordo com Cohn (2001:51), o SUS deverá obedecer algumas diretrizes básicas e enfrentar questões bem complexas, como:

口 o implemento de medidas para que os princípios do SUS se viabilizem e se concretizem, de forma a torná-lo uma realidade irreversível;

口 a descentralização, princípio norteador do SUS, devendo ser entendida como repasse de recursos e delegação de poder para que os níveis estadual e municipal formulem a política de saúde correspondente, de acordo com prioridades que respondam à especificidade local, mas que obedeçam, ao mesmo tempo, as diretrizes nucleares formuladas para o âmbito nacional;

口 Se do ângulo das normas institucionais a descentralização já é uma realidade hoje, vale recordar que como questão ela é eminentemente política, a tradição do uso desses recursos para fins político-clientelísticos continua presente. Há, portanto, que se montar estratégias de curto, médio e longo prazos para a sua implementação;

\footnotetext{
${ }^{2}$ Dispõe sobre a participação da comunidade na gestão do Sistema Único de Saúde (SUS) e sobre as transferências intergovernamentais de recursos financeiros na área da saúde. Disponível em: <http://conselho.saude.gov.br/legislacao>. Acesso em: 20 out. 2004.
} 
口 enfrentar a questão orçamentária. O Ministério da Saúde passa a receber recursos de várias fontes encaminhados ao Fundo Nacional de Saúde: orçamento de seguridade social, da União, dos estados, dos municípios e do Distrito Federal, acrescido de outras fontes. Embora essa soma constitua um fundo único, o controle de cada uma delas como aporte para o FNS (o mesmo valendo para os fundos estadual e municipal) deve ser bastante destacado e enfatizado. Caso contrário, o emaranhado dos cálculos financeiros deixará indiferenciados, mais uma vez, os setores que estão "pagando a conta", impossibilitando o controle público sobre reduções orçamentárias, por exemplo;

૫ a proposta do SUS implica a criação dos conselhos nacional, estadual e municipal de saúde, compostos por representantes do governo e da sociedade (usuários, trabalhadores em saúde e prestadores de serviços);

口 ganha importância a função do Ministério da Saúde dar suporte técnico e colaborar na formação de recursos humanos para que as novas tarefas que o SUS demanda nos níveis estadual e municipal possam ser cumpridas; da mesma forma a área de pesquisa, resguardada sua autonomia, deverá contemplar também a produção de conhecimento requerida pelas novas diretrizes da política de saúde.

Para essa autora, associadas às diretrizes referidas, que demandam tempo para sua implementação, e que, muitas vezes, constituem-se em requisitos para outras diretrizes, questões mais imediatas e urgentes também devem ser contempladas no rol de prioridades do setor saúde, como:

- as doenças endêmicas, algumas delas apresentando uma tendência ascendente, devem ser enfrentadas com medidas específicas da área de saúde associadas às demais da área social, tendo como suporte essencial uma política econômica redistributiva;

口 a saúde do trabalhador, não só em termos de assistência médica, mas, sobretudo, de fiscalização do ambiente e condições de trabalho. MPAS, MS e MT terão de atuar conjuntamente para garantir os direitos dos trabalhadores;

口 continuar buscando mecanismos para resgatar a credibilidade do setor público capaz de gerir a saúde; 
[ estabelecer e aperfeiçoar critérios para cálculo do volume de recursos a serem repassados para os estados e municípios que contemplem a dimensão da população e da rede instalada e possibilitem que as áreas mais desprovidas de equipamentos de saúde sejam priorizadas (Cohn, 2001:54).

Entretanto, para tentar modificar o quadro que se apresenta na área da saúde, é necessário debatê-lo na esfera pública da política, ou seja, com a participação do Legislativo, dos partidos políticos, dos setores organizados da sociedade, dos profissionais da área, como forma de fazer frente à resistência para efetivação da saúde como direito de cidadania.

Segundo Elias (2001), o debate travado na atualidade em relação à saúde tem se concentrado nas formas de reorganização do setor e na divisão de responsabilidades entre os setores público e privado, evidenciando a melhoria na resolutividade dos serviços prestados e a descentralização como as alternativas mais efetivas para concretizá-las.

Acrescente-se ao debate, no Brasil, as questões relacionadas ao financiamento do setor, no que diz respeito à definição dos recursos e às fontes para provê-lo, além dos problemas relacionados ao gerenciamento dos serviços.

Assim, conforme Elias (2001:69),

os problemas relativos à estruturação e funcionamento do SUS são muitos e variados: a descentralização ocorre de modo limitado e limitante; o financiamento continua pendente em termos quantitativos (o montante de recursos disponíveis) e qualitativos (estabilidade e tipo de fontes de recursos); o controle social busca abrir caminhos em meio a uma sociedade desestimulada para as ações de cidadania e a um Estado desacostumado a ter seus atos controlados pela sociedade, portanto a um Estado infenso ao controle público... Em conseqüência, a menção ao sistema de saúde, no caso brasileiro, implica muito mais o enunciado de um discurso sobre o que deveria ser ou sobre aquilo que se pretende estruturar, portanto, no domínio do campo das idéias, do que propriamente sobre aquilo que realmente é, dado que a forma atual de organização dos serviços não fornece qualquer base empírica para configurá-los sequer como partes articuladas de um conjunto, objetivando atender às necessidades socialmente demandadas em relação à saúde, sendo que desta situação não escapam sequer 
os serviços de saúde governamentais, que em seu conjunto ainda carecem de articulação e organização.

A esfera pública é responsável pela grande maioria dos serviços voltados para a atenção básica de saúde, que incorpora tecnologia de baixo custo e complexidade. Em contrapartida, o setor privado concentra-se principalmente na atenção secundária e terciária, ou seja, nos atendimentos por meio de policlínicas e hospitais, os quais demandam tecnologia de maior complexidade e custo. A exceção fica por conta dos serviços de alta complexidade, que pertencem à esfera pública, a exemplo do Incor (SP) e Sara Kubitschek (Brasília). ${ }^{3}$

Entretanto, é importante evidenciar que a lógica da prestação dos serviços não acompanha a lógica do financiamento, uma vez que o Estado se constitui na principal fonte financiadora, realizando a cobertura financeira de grande parte dos serviços prestados pelos hospitais, sejam eles públicos ou privados. Quanto à atenção secundária, $12,5 \%$ do total da rede estão distribuídos regionalmente de forma bastante desigual, ou seja, $67 \%$ dos estabelecimentos estão situados nas regiões Sul e Sudeste que concentram $59 \%$ da população. ${ }^{4}$

Essa realidade chama a atenção para o caráter mercantilista da prestação de serviços de saúde, evidenciando que a oferta de serviços, não raro, passa ao largo dos perfis de morbimortalidade das regiões brasileiras e das demandas da população no que se refere ao acesso e à cobertura dos serviços de saúde.

A cobertura na área da saúde, implementada pelas políticas sociais públicas, reflete o processo de reestruturação dos serviços públicos de cunho neoliberal implementado no país e reforçam o quadro existente de desigualdades.

Não resta dúvida que, na última década, o setor saúde foi um dos mais atingidos pelo corte de verbas governamentais, assim como os demais campos da área social, como demonstra Lesbaupin e Mineiro (2002:39) na tabela 3.

\footnotetext{
${ }^{3}$ A rede assistencial do SUS no Rio Grande do Norte possui 174 centros de saúde, 412 postos de saúde e 37 policlínicas (Fonte: Sistema de Informações Ambulatoriais — SIA/SUS, 2003. Disponível em: <www.saude.rn.gov.br>. Acesso em: 28 nov. 2004).

A rede hospitalar do SUS no Rio Grande do Norte é composta por 100 hospitais públicos, 73 privados e quatro universitários (Fonte: Sistema de Informações Hospitalares - SIH/SUS, 2003. Disponível em: <www.saude.rn.gov.br>. Acesso em: 28 nov. 2004).

${ }^{4}$ Dados da Pesquisa Nacional de Amostragem em Domicílio (Pnad), 1990 (Elias, 2001:79).
} 


\begin{tabular}{|lcccccc}
\hline \multicolumn{7}{c}{ Tabela 3 } \\
\multicolumn{7}{l}{$\begin{array}{l}\text { Percentual da despesa social em relação } \\
\text { Discriminação orçamento líquido total }\end{array}$} \\
\hline Saúde/saneamento & 1995 & 1996 & 1997 & 1998 & 1999 & 2000 \\
Educação/cultura & 4,8 & 4,5 & 4,3 & 3 & 4 & 3,3 \\
Habitação/urbanismo & 3 & 2,8 & 2,5 & 2,7 & 3,4 & 1,8 \\
Assistência/previdência & 0,03 & 0,1 & 0,1 & 0,02 & 0,07 & 0,14 \\
\end{tabular}

Fontes: Siafi/ SNT-CD e Prodasen. Dados elaborados por Ivo Lesbaupin com base no orçamento líquido total e na despesa social 1995-2001 — dados levantados pelo Inesc.

Assim, nos anos 1990 o que se tem, com base em Lesbaupin e Mineiro (2002), é uma reforma do setor subordinada à proposta do Banco Mundial, que entende a saúde não como um direito gratuito de todo e qualquer cidadão, mas como um setor que deve ser focalizado e seletivo no atendimento aos mais pobres.

Em outras palavras, uma esfera onde se deve priorizar o ajuste fiscal, subordinando os princípios da eqüidade aos da eficiência, efetividade e economia nos gastos públicos.

Ainda segundo Lesbaupin e Mineiro (2002:44), também na área da saúde,

a saída para uma suposta crise é a privatização. Parece, na ótica neoliberal que o mercado cuida melhor de tudo: de empresas siderúrgicas, petrolíferas, da previdência, da saúde e da educação. A experiência da população que já fez uso dos serviços privatizados não confirma a tese anterior. Segundo o Idec, há cinco anos os planos e seguros de saúde lideram o ranking de queixas e consultas, à frente dos bancos e da telefonia (Jornal do Brasil, 31 mar. 2002). Mas, há mais grave: doenças previamente erradicadas no Brasil vêm retornando, em taxas epidêmicas. Segundo o Datasus, o dengue, erradicado nos anos 50, apresentou uma taxa de incidência acima de 100 por $100 \mathrm{mil}$ habitantes: 159,73 (1997), 140,82 (1998), 127,89 (1999), 141,27 (2000). A tuberculose, embora não tão grave quanto o dengue, também apresenta taxas altas: 52,19 por 100 (1997), 51,26 (1998), 65,69 (1999) e 60,70 (2000). Além destas houve recrudescimento de endemias como a malária, a leishmaniose e a hanseníase (conforme Carvalho, 2002; Kerstenetzky, 2000).

Em outras palavras, os indicadores de saúde no Brasil apresentam um quadro preocupante, resultante do modelo de desenvolvimento excludente implementado, principalmente, na última década, e que se tra- 
duz na falta de efetividade das políticas públicas em geral e no setor saúde, em particular.

Nesse sentido, observa-se, de acordo com Cohn e Elias (2001), que há um aumento na incidência de doenças que são passíveis de controle, por um lado, e, por outro, uma ampliação de sua distribuição geográfica e em novos grupos sociais. Além do mais, intensifica-se no perfil de morbimortalidade doenças que podem ser classificadas como típicas do setor urbano, tais como do aparelho circulatório e neoplasmas.

De acordo com os dados do Ministério da Saúde para 1999, ${ }^{5}$ a mortalidade proporcional para as principais causas de doenças evidencia as do aparelho circulatório com $32 \%$, diabetes mellitus com $19,3 \%$, os neoplasmas com $15 \%$, as do aparelho respiratório com $11 \%$, as infecciosas e parasitárias com $6 \%$ e diarréicas agudas com 5,5\%, e as demais externas com $15 \%$.

Significa dizer que o quadro sanitário brasileiro apresenta uma combinação de doenças infantis e infecto-contagiosas com doenças crônicodegenerativas, que variam em incidência tanto em termos regionais, quanto no que se refere às variáveis de renda, tendo esta última um aspecto decisivo.

Em outras palavras, onde a pobreza e a exclusão são mais incisivas, a mortalidade por doenças típicas dessa condição social se faz presente, ao contrário de onde as condições de vida e de renda são melhores.

Nessa ótica, o setor saúde necessita tanto de medidas preventivas, de caráter coletivo, quanto de atenção médica de alta complexidade tecnológica. Assim, é preciso superar a dicotomia entre as ações de caráter individual e as de caráter coletivo, que levam à setorialização da política de saúde em programas estanques.

É necessário, ainda, formular políticas de saúde articuladas às outras políticas até porque, se, por um lado, as primeiras têm sérias limitações em função da realidade brasileira, por outro, a própria definição do conceito de saúde num sentido mais amplo exige que suas políticas sejam elaboradas tendo como parâmetro a unificação às demais políticas.

Compreende-se, assim, que existem grandes e graves problemas para o enfrentamento da problemática de saúde existente no Brasil, sejam derivados de questões estruturais, dada a condição de país capitalista periférico e dependente, sejam originados pela opção política adotada por governantes e elites dominantes no trato da questão da saúde brasileira.

Essas determinações - responsáveis pela situação em que se encontra a saúde no Brasil - delineiam o quadro existente na área da saúde no país, assim como permeiam as demandas que são postas para os serviços de saúde.

\footnotetext{
${ }^{5}$ Ministério da Saúde. Disponível em: <www.saude.gov.br>. Acesso em: 8 nov. 2004.
} 


\section{As (re)configurações das demandas postas ao serviço social no âmbito dos serviços públicos de saúde}

As demandas postas para o serviço social na esfera pública, a partir dos anos 1990, refletem as mudanças processadas no mundo do trabalho e a forma como são implementadas as políticas sociais públicas, em um contexto de desresponsabilização do Estado com a proteção social e de intensificação da questão social. Essa realidade propiciou um redimensionamento das demandas postas aos assistentes sociais, tanto em relação a novas demandas quanto às tradicionais.

No entender de Mota e Amaral (2000a:25), as demandas "são requisições técnico-operativas que, através do mercado de trabalho, incorporam as exigências dos sujeitos demandantes", ou seja, "elas comportam uma verdadeira 'teologia' dos requisitantes a respeito das modalidades de atendimento de suas necessidades".

Nessa perspectiva, a legitimidade do serviço social, enquanto profissão inserida na divisão social e técnica do trabalho, passa, fundamentalmente, pela sua capacidade de responder às necessidades sociais que são fonte de sua demanda (Iamamoto, 2002).

Para Mota e Amaral (2000a), essas demandas devem ser problematizadas no sentido de possibilitar a compreensão das mediações que relacionam as necessidades fundamentais do processo de reestruturação produtiva com as requisições do mercado de trabalho profissional.

Assim, é condição sine qua non que os assistentes sociais identifiquem o conjunto das necessidades dos sujeitos demandantes - capital e trabalho - e contextualize-as no capitalismo contemporâneo.

É a partir do conhecimento dessas necessidades, e das determinações que as originam, que os assistentes sociais constroem o lastro que possibilita dar conta das requisições postas no seu cotidiano profissional pelo mercado de trabalho.

Logo, é necessário entender que as demandas colocadas para o cotidiano profissional do assistente social resultam das seqüelas originadas pela sociedade capitalista e que a capacidade de resposta ao atendimento das demandas por esses profissionais está diretamente vinculada, mas não só, ao projeto hegemônico que foi colocado para a sociedade brasileira nestes últimos anos.

Outrossim, tem-se um realinhamento das demandas existentes, seja em função do descompasso entre a retração na oferta dos serviços e aumento da demanda, seja em função da reestruturação dos serviços públicos, ou, ainda, da redução de postos de trabalho, como se deu na última década, particularmente no âmbito federal. 
Essas determinações vão suscitar novas configurações às demandas dirigidas ao serviço social, entre as quais, um deslocamento cada vez maior das demandas da esfera do atendimento para a esfera do não-atendimento, isto é, um aumento no volume das demandas decorrentes da impossibilidade de acesso às políticas públicas.

Note-se que a agudização das expressões da questão social influencia sobremaneira as demandas que são postas para o fazer dos assistentes sociais, tanto no que se refere ao volume quanto à sua complexificação, uma vez que aumenta o leque de necessidades da população que busca as políticas públicas, bem como amplia a diversidade em torno dessa população, ou seja, outros setores e não mais apenas os pobres e miseráveis passam a procurar os serviços públicos, vitimados também pelas transformações societárias da última década.

Outro aspecto que interfere nas demandas colocadas para o serviço social se refere à redução de profissionais tanto de serviço social quanto de áreas afins, ou seja, os assistentes sociais necessitam reorganizar o atendimento das demandas em função do número de profissionais, por um lado, e, por outro, absorver, em alguns casos, atribuições antes dirigidas a outros profissionais, principalmente na área de recursos humanos.

Além do mais, em face da reestruturação dos serviços, novas demandas vão estar colocadas em outras esferas de governo, explicitamente a municipal, em função da descentralização e municipalização dos serviços, que abre novas perspectivas de trabalho para o conjunto dos assistentes sociais, em função da "tendência de interiorização da demanda pelo trabalho do assistente social" (Trindade, 1999:217).

No caso da saúde, em particular, as demandas dirigidas ao serviço social em função do processo de municipalização das ações de saúde têm se traduzido "na montagem das estruturas organizacionais e na mobilização da sociedade civil para a constituição dos conselhos de saúde" (Trindade, 1999:217).

Ainda com base em Trindade (1999), o processo de descentralização administrativa e de municipalização das políticas sociais públicas tem apontado para a ampliação do espaço sócio-ocupacional dos assistentes sociais em atribuições relativas à formulação, à gestão e à avaliação de políticas sociais, particularmente no âmbito municipal, com uma tendência de ascensão para os escalões médios e superiores do poder organizacional.

Note-se que no setor saúde, mesmo as demandas que tradicionalmente são dirigidas ao serviço social, ou seja, aquelas que requerem uma prestação direta dos serviços públicos de saúde são tangenciadas por novas determinações, derivadas das mudanças societárias em âmbito mais geral e pelas contradições inerentes ao SUS, numa esfera mais particular. 
Significa dizer que antagonismos como universidade/seletividade, integralidade/focalização e ampliação de direitos/falta de investimentos no setor saúde estão refletidos nas demandas postas para o serviço social, atribuindolhes novas configurações.

Por outro lado, a população que prioritariamente demanda as ações do serviço social interfere de maneira incisiva nas demandas colocadas para o fazer do assistente social, uma vez que ele se constitui, substancialmente, dessa população excluída do modelo de desenvolvimento colocado para a sociedade brasileira e que faz parte das estatísticas das doenças oriundas da fome, da miséria, da falta de teto, da falta de água potável e saneamento básico, da falta de trabalho e de renda, da violência, enfim, da inexistência de condições aceitáveis de vida.

São essas pessoas, com as mais variadas demandas, que acorrem ao Sistema Único de Saúde em busca de respostas às suas necessidades e que iniciam ou terminam sua caminhada na sala do serviço social.

Para Lessa (2003), a implantação do SUS possibilitou uma expansão do mercado de trabalho para os assistentes sociais na esfera da saúde pública, decorrente, principalmente, do processo de municipalização.

É importante evidenciar que esse aumento de postos de trabalho no SUS vem acompanhado da precarização do trabalho no que se refere às relações trabalhistas e reduções salariais.

Quanto às demandas postas para o trabalho do assistente social, Costa (Lessa e Costa, 2003) entende que decorrem fundamentalmente da necessidade de administrar as contradições inerentes ao SUS, no que se refere ao processo de racionalização e reorganização do sistema.

No dizer de Lessa (Lessa e Costa, 2003:78),

o produto principal do seu trabalho é a recomposição da integralidade das ações do sistema, ainda que por caminhos tortuosos e também invisíveis. Assim, a matéria-prima sobre a qual incide o trabalho do assistente social no SUS tem sido, prioritariamente, as contradições, dificuldades de funcionamento e a falta de resolutividade do sistema social (...) Nessa lógica de análise, a legitimidade do serviço social se constrói pelo avesso, ou seja, a sua utilidade se afirma nas contradições fundamentais da política de saúde.

Ou seja, o assistente social no interior do SUS é o profissional cujo exercício profissional está permeado pelas tentativas de equacionar direitos, reivindicações e necessidades da população demandante à falta de resolutividade do setor desde os procedimentos mais simples até os mais complexos. 
É nessa realidade que o assistente social, profissional executor das políticas sociais públicas, tem que dar respostas às demandas postas ao seu exercício profissional para uma população que dispõe, como única alternativa de sobrevivência, de serviços completamente desmontados e cada vez mais distanciados da função social que lhes compete.

$\mathrm{O}$ assistente social e os demais profissionais que atuam nessa área o fazem em condições difíceis, colocando-se como mediadores entre uma população miserabilizada, que traz consigo as mazelas de um sistema excludente, cujas políticas sociais públicas implementadas são sinônimo de escassez, de falta de resolutividade, de descaso das elites dominantes para com a população demandante desses serviços públicos.

Em outras palavras, as demandas postas por essa população se colocam, em volume e complexidade, muito superiores à cobertura que o Estado se propõe a efetivar e, nessa ótica, as demandas que são postas para o trabalho do assistente social refletem exatamente esse descompasso, uma vez que a população demandante das políticas sociais públicas apresenta solicitações que essas políticas não têm condições de atender ou o fazem de forma precária e desqualificada.

Enfim, o assistente social tem que fazer a mediação entre demandas que resultam das condições de vulnerabilidade a que está submetida a população e as demandas postas pela instituição, responsável pela implementação das políticas sociais públicas, que se configuram dentro de uma perspectiva focalista, seletiva e excludente para a prestação dos serviços públicos.

\section{Conclusões}

O delineamento realizado sobre as demandas postas para o serviço social aponta que é fundamental a construção coletiva de contrapontos que sinalizem para a construção, ampliação e consolidação de direitos, com a participação e controle da sociedade na definição e implementação de políticas públicas de caráter universalizante.

Assim, os assistentes sociais como sujeitos históricos necessitam efetivar o seu exercício profissional, procurando buscar articular o miúdo do cotidiano com as questões afetas ao ajuste neoliberal e suas perspectivas mercadológicas e privatizantes.

Assim, é fundamental que os profissionais tenham clareza dos projetos que estão postos, o que eles significam e suas conseqüências. Isso quer dizer que o assistente social, como profissão inserida na divisão social e técnica do trabalho, pode no seu exercício profissional reforçar o projeto neoliberal com 
suas políticas seletivas, excludentes e focalistas, que visam ampliar a esfera privada em detrimento da esfera pública, contribuindo para minar os direitos daqueles que demandam seu trabalho para o atendimento de suas necessidades; ou, ao contrário, reforçar o projeto que defende o acesso universal, igualitário, integral e de qualidade das populações demandantes das políticas sociais públicas, contribuindo para que o seu trabalho efetive ações que apontem para o fortalecimento dos sujeitos coletivos dos direitos sociais.

Em outras palavras, é fundamental uma leitura atenta das determinações sociais, históricas, econômicas, políticas e culturais nas expressões da questão social na saúde e, especialmente, das limitações da intervenção profissional nos processos relacionados ao binômio saúde-doença, uma vez que eles estão atrelados aos processos societários em nível macro.

\section{Referências bibliográficas}

BRASIL. Constituição da República Federativa. Brasília: Senado Federal, 1988.

.Lei no 8.080/90. Dispõe sobre as condições para a promoção, a proteção e a recuperação da saúde, a organização e o funcionamento dos serviços correspondentes, definindo os parâmetros para o modelo assistencial e estabelecendo os papéis das três esferas de governo. Disponível em: <www.ensp.fiocruz.br>. Acesso em: 20 out. 2004.

Lei no ${ }^{8} .142 / 90$. Dispõe sobre a participação da comunidade na gestão do Sistema Único de Saúde (SUS) e sobre as transferências intergovernamentais de recursos financeiros na área da saúde. Ministério da Saúde. Conselho Nacional de Saúde. Disponível em: <http://conselho.saude.gov.br/legislacao>. Acesso em: 20 out. 2004.

COHN, Amélia. A saúde na Previdência Social e na seguridade social: antigos estigmas e novos desafios. In: COHN, Amélia; ELIAS, Paulo E. Saúde no Brasil: políticas e organização de serviços. 4. ed. São Paulo: Cortez/Cedec, 2001.

ELIAS, Paulo E. Estrutura e organização da atenção à saúde no Brasil. In: COHN, Amélia; ELIAS, Paulo E. Saúde no Brasil: políticas e organização de serviços. 4. ed. São Paulo: Cortez/Cedec, 2001.

IAMAMOTO, Marilda Vilela. O serviço social na contemporaneidade: trabalho e formação profissional. São Paulo: Cortez, 1998.

. Projeto profissional, espaços ocupacionais e trabalho do assistente social na atualidade. In: Atribuições privativas do(a) assistente social em questão. Brasília, 2002. 
LESSA, Ana Paula Girão; COSTA, Liduína Farias A. (Orgs.). O serviço social no Sistema Único de Saúde. Fortaleza: Uece, 2003.

LESBAUPIN, Ivo; MINEIRO, Adhemar. O desmonte da Nação em dados. Petrópolis: Vozes, 2002.

MINISTÉRIO DA SAÚDE. Rede assistencial do SUS. Disponível em: <www.saude.gov.br>. Acesso em: 15 mar. 2004.

Indicadores de mortalidade geral. Disponível em: <www.saude.gov.br>. Acesso em: 8 nov. 2004

Sistema de informações hospitalares - SIH/SUS. 2003. Disponível em: <www.saúde.rn.gov.br>. Acesso em: 28 nov. 2004.

Sistema de informações ambulatoriais - SIA/SUS. 2003. Disponível em: <www.saude.rn.gov.br>. Acesso em: 28 nov. 2004.

Indicadores de mortalidade infantil. Disponível em: <www.portal.saude.gov.br/ saude/aplicações/anuario2001>. Acesso em: 27 nov. 2004.

MOTA, Ana Elizabete; AMARAL, Ângela Santana do. Reestruturação do capital, fragmentação do trabalho e serviço social. In: A nova fábrica de consensos: ensaios sobre a reestruturação empresarial, o trabalho e as demandas ao serviço social. 2. ed. São Paulo: Cortez, 2000a.

NETTO, José Paulo. FHC e a política social: um desastre para as massas trabalhadoras. In: O desmonte da Nação: balanço do governo FHC. 3. ed. Petrópolis: Vozes, 2000.

TANAKA et al. Gerenciamento no setor saúde na década de 80 no estado de São Paulo. Revista de Saúde Pública, São Paulo, n. 3, 1992. Disponível em: <www.scielosp.org > . Acesso em: 15 mar. 2004.

TOMAZI, Zelma Francisca Torres. O que todo cidadão precisa saber sobre saúde e Estado brasileiro. São Paulo: Global, 1986.

TRINDADE, Rosa Prédes. Desvendando o significado do instrumental técnico-operativo na prática profissional do serviço social. 1999. Tese (Doutorado em Serviço Social) — UFRJ, Rio de Janeiro, 1999. 